\title{
Management of early gastric cancer with positive horizontal or indeterminable margins after endoscopic submucosal dissection: multicenter survey
}

\section{두(ㅇ) $\odot$}

Authors

Naoki Ishii ${ }^{1}$, Fumio Omata ${ }^{1}$, Junko Fujisaki ${ }^{2}$, Toshiaki Hirasawa ${ }^{2}$, Mitsuru Kaise ${ }^{3}$, Shu Hoteya ${ }^{3}$, Satoshi Tanabe ${ }^{4}$, Kenji Ishido ${ }^{4}$, Ken Ohata ${ }^{5}$, Maiko Takita ${ }^{5}$, Tetsuya Mine ${ }^{6}$, Muneki Igarashi ${ }^{6}$, Tatsuya Yoshida ${ }^{7}$, Yuichi Takeda ${ }^{8}$, Yohei $^{3}$ Furumoto $^{9}$, Kenshi Matsumoto ${ }^{10}$, Naohisa Yahagi ${ }^{11}$, Hirotaka Nakashima ${ }^{12}$, Tomonori Wada ${ }^{13}$, Tomoko Tagata ${ }^{14}$, Atsushi Mitsunaga ${ }^{14}$

Institutions

1 Department of Gastroenterology, St. Luke's International Hospital, Tokyo, Japan

2 Department of Gastroenterology, Cancer Institute Hospital, Tokyo, Japan

3 Department of Gastroenterology, Toranomon Hospital, Tokyo, Japan

4 Department of Gastroenterology, Kitasato University East Hospital, Kanagawa, Japan

5 Department of Gastroenterology, NTT Medical Center Tokyo, Tokyo, Japan

6 Department of Gastroenterology, Tokai University School of Medicine, Kanagawa, Japan

7 Department of Surgery, Kudanzaka Hospital, Tokyo, Japan

8 Department of Gastroenterology, Koritsu Showa Hospital, Tokyo, Japan

9 Department of Internal Medicine, Tokyo Metropolitan Bokutoh Hospital, Tokyo, Japan

10 Department of Gastroenterology, Juntendo University School of Medicine, Tokyo, Japan

11 Division of Research and Development for Minimally Invasive Treatment, Cancer center, Keio University School of Medicine, Tokyo, Japan

12 Department of Gastroenterology, Foundation of detection of early gastric carcinoma, Tokyo, Japan

13 Department of Gastroenterology, Sanraku Hospital, Tokyo, Japan

14 Department of Endoscopy, Tokyo Women's Medical University Yachiyo Medical Center, Chiba, Japan

submitted 29.7.2016

accepted after revision 13.1.2017

\section{Bibliography}

DOI http://dx.doi.org/10.1055/s-0043-104859 |

Endoscopy International Open 2017; 05: E354-E362

(c) Georg Thieme Verlag KG Stuttgart · New York

ISSN 2364-3722
Corresponding author

Naoki Ishii, MD, Department of Gastroenterology,

St. Luke's International Hospital, 9-1 Akashi-cho,

Chuo-ku, Tokyo 104-8560, Japan

Fax: +81-3-3544-0649

naoishi0328@gmail.com

\section{ABSTRACT}

Background and study aims Positive horizontal margins in resected specimens are sometimes encountered after endoscopic submucosal dissection (ESD) for early gastric cancers, and appropriate treatment strategies for these cases are not established. The aim of this study was to evaluate current empirical treatments for patients with positive horizontal or indeterminable margins after ESD.

Patients and methods We performed a multicenter survey and data from 14 hospitals were collected. The pooled proportions of positive horizontal or indeterminable margins and those of patients followed up without early intervention were calculated using a logistic-normal random-effects model. For calculating pooled estimates, subgroup analyses of high- and non-high-volume centers were conducted.

Results A total of 11,796 ESD cases were enrolled and 229 patients ( $2 \%$ ) had positive horizontal or indeterminable margins. Ninety-eight cases were treated within 30 days of ESD and 131 cases were followed up without early treatments. Pooled estimates of positive margins in high- and non-highvolume centers were $1 \%(95 \% \mathrm{Cl}: 1 \%-2 \%)$ and $2 \%(95 \% \mathrm{Cl}$ : $1 \%-4 \%)$, respectively, and were not heterogeneous ( $P=$ $0.191)$. The proportion of patients followed up without early intervention ranged from $30 \%$ to $100 \%$. The pooled estimate was $68 \%$ ( $95 \% \mathrm{Cl}: 50 \%-83 \%)$. The pooled estimates of high- and non-high-volume centers were $65 \%$ (95\% Cl: $38 \%-85 \%)$ and $72 \%(95 \% \mathrm{Cl}: 44 \%-89 \%)$, respectively, and were not heterogeneous $(P=0.692)$.

Conclusion There was insufficient consensus regarding treatment strategies used for early gastric cancer with positive horizontal or indeterminable margins after ESD. Further studies are required to establish a consensus. 


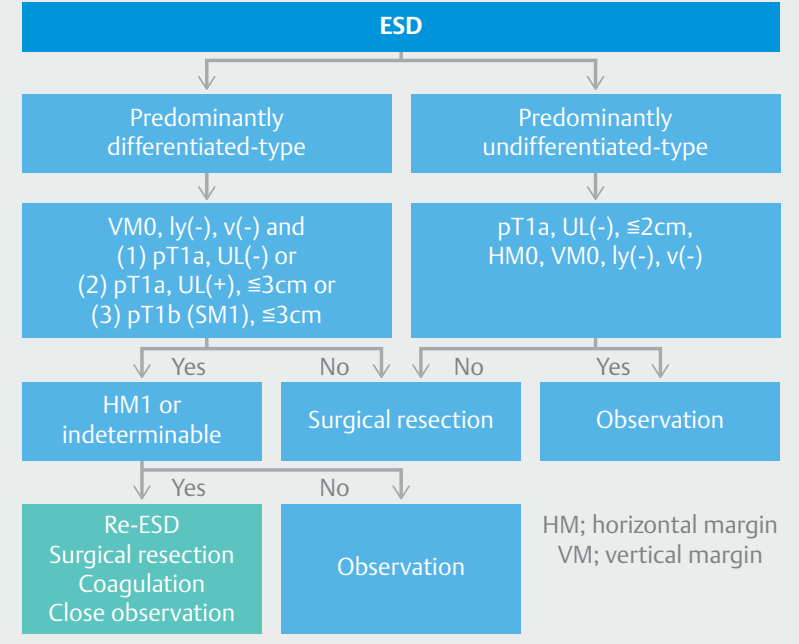

- Fig. 1 Treatment strategies after endoscopic submucosal dissection (ESD) for early gastric cancer.

\section{Introduction}

Endoscopic submucosal dissection (ESD) was introduced for treating early gastric cancer with a minimal risk of regional lymph node and distant metastases [1]. ESD is currently performed worldwide because neoplasms can be resected en bloc, and a detailed pathological assessment of resected specimens can be performed [1,2]. However, positive horizontal margins in the resected specimens are sometimes encountered after ESD [1 -9]. Nevertheless, appropriate treatment strategies for differentiated-type gastric cancers with positive horizontal or indeterminable margins after ESD have not yet been established ( Fig. 1) [10]. The aim of this study was to estimate the probability of positive horizontal or indeterminable margins after ESD and evaluate the current empirical treatments for the patients with positive horizontal or indeterminable margins after ESD. We performed a multicenter survey of the treatment strategies for early gastric cancer with positive horizontal or indeterminable margins after ESD.

\section{Patients and methods}

Data from 14 hospitals (Cancer Institute Hospital, Toranomon Hospital, Kitasato University East Hospital, NTT Medical Center Tokyo, St. Luke's International Hospital, Tokai University School of Medicine, Kudanzaka Hospital, Koritsu Showa Hospital, Tokyo Metropolitan Bokuto Hospital, Juntendo University School of Medicine, Tokyo Women's Medical University Yachiyo Medical Center, Keio University School of Medicine, Foundation of Detection of Early Gastric Carcinoma, and Sanraku Hospital) that participated in the 30th endoscopic gastric mucosal resection (EGMR) conference were collected. The contents of the questionnaires in the current study are demonstrated in - Fig. $\mathbf{S 1 .}$
EGMR conference is a well-known research conference focusing on endoscopic therapy for early gastric cancer, which has been held biannually since 2000 in Tokyo, Japan and many endoscopists from more than 20 medical centers usually attend the conference. These institutions covered medical centers where the majority of endoscopists with expertise in ESD were working in Tokyo. Actually, at least 8 ESD opinion leaders worked in these institutions. It was expected that these doctors' behaviors would reflect current empirical therapeutic strategies after ESD in Japan. Survey questionnaires were sent to the representatives of each institution. Replies to our questionnaires and approval by the institutional review board (IRB) for the study were obtained from 14 institutions.

The proportion of patients with positive horizontal or indeterminable margins and the proportion of patients who were followed up without early interventions were calculated for each institution. Two-sided or 1 -sided $95 \%$ confidence intervals (Cls) of those proportions were also calculated. Meta-analyses for proportions were performed to calculate pooled estimates of the above mentioned 2 proportions. The pooled proportions of positive horizontal or indeterminable margins and those of the patients who were followed up without early intervention were calculated by a logistic-normal random-effects model [11]. For calculating pooled estimates, subgroup analyses of high- and non-high-volume centers were also conducted. A high-volume center was defined as an institution with more than 100 ESD cases per year. All analyses were performed by STATA $^{\circledR}$ version 14.1 (StataCorp, College Station, TX, USA).

\section{Results}

A total of 11,796 differentiated-type gastric adenocarcinomas that met the absolute or expanded indication for ESD in the Japanese gastric cancer treatment guidelines 2010 (tumors clinically diagnosed as T1a and either no ulcer findings regardless of size or positive ulcer findings in tumors sized $\leq 3 \mathrm{~cm}$ in diameter) [10] were treated with ESD from September 2002 to May 2014. Positive horizontal or indeterminable margins were observed in 235 resected specimens pathologically (2.0\%). Six cases in which the description in the questionnaire was incomplete were excluded from the study, and 229 cases were enrolled. The treatment strategies were evaluated in 229 cases with positive horizontal or indeterminable margins using obtained questionnaires.

The number of total ESD cases and that of early gastric cancer with horizontal or indeterminable margins after ESD in each institution are presented in $>$ Table $\mathbf{S 1}$.

Pooled estimates of positive or indeterminable margins in 14 institutions are demonstrated in $\mathbf{F i g . 2}$. Institutions 1 to 4 and 6 were allocated as high-volume centers. The proportion of patients with horizontal or indeterminable margins ranged from $0.6 \%$ to $11 \%$. The pooled estimate of positive horizontal or indeterminable margins was $2 \%(95 \% \mathrm{Cl}: 1 \%-3 \%)$. The pooled estimates of positive margins in high- and non-high-volume centers were $1 \%(95 \% \mathrm{Cl}: 1 \%-2 \%)$ and $2 \%(95 \% \mathrm{Cl}: 1 \%-4 \%)$, respectively. Pooled estimates of these subgroups were marginally heterogeneous $(P=0.191)$. 


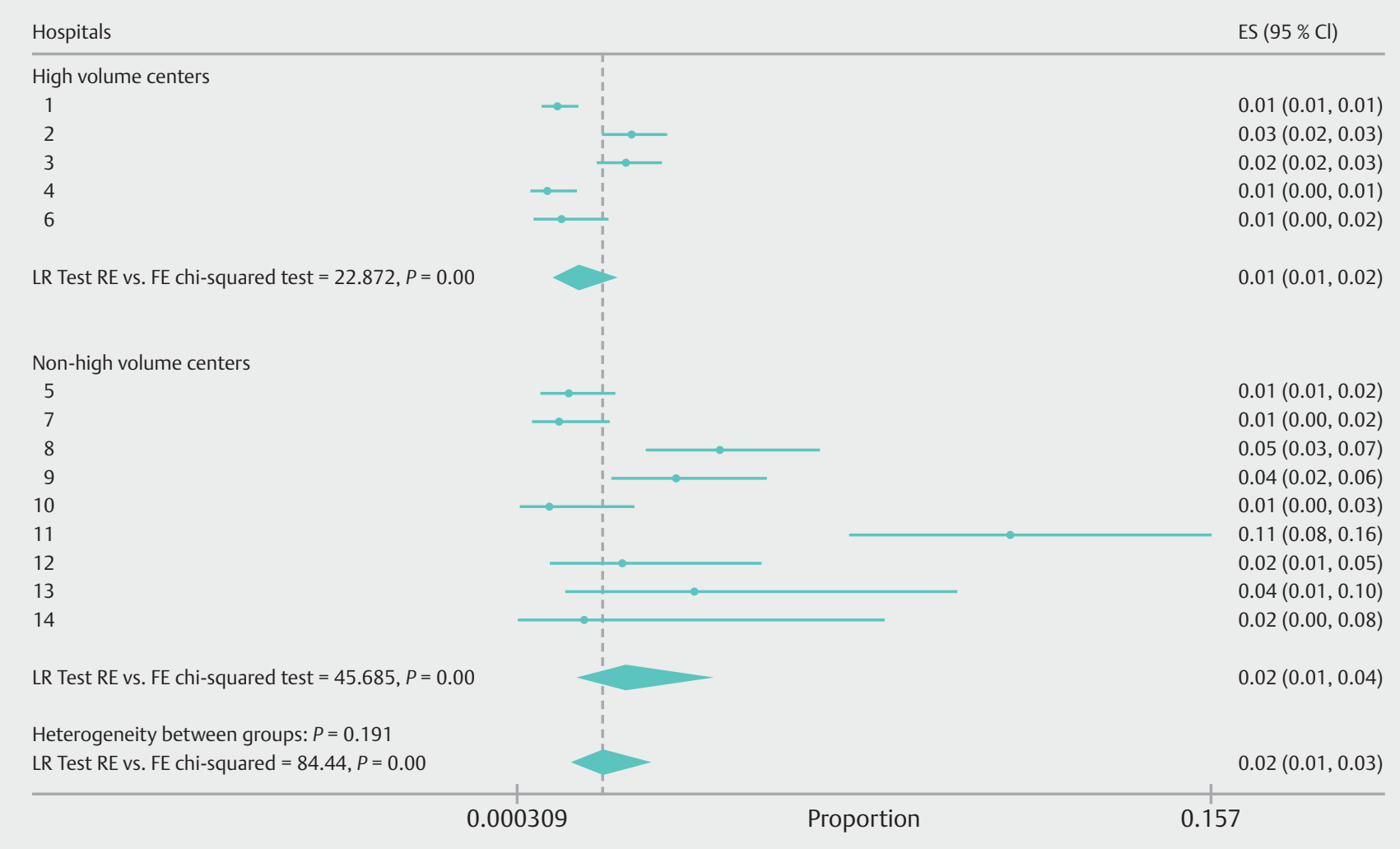

Fig. 2 Pooled estimates of positive or indeterminable margins in high and non-high volume centers.

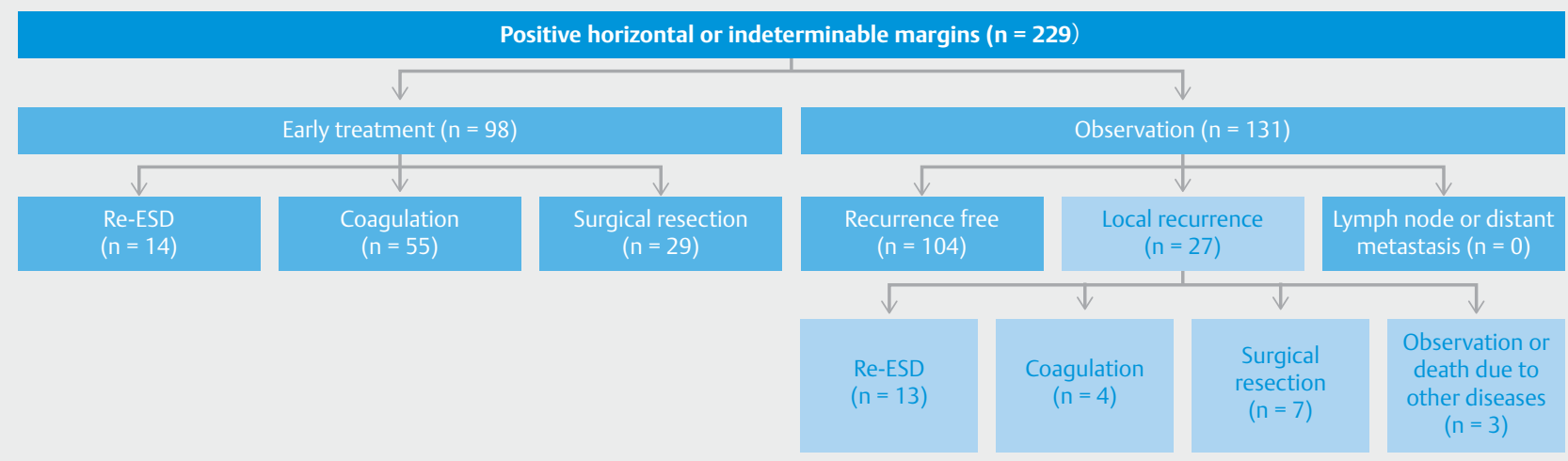

Fig. 3 Treatment strategy for early gastric cancer with positive horizontal or indeterminable margins after endoscopic submucosal dissection (ESD).

The treatment strategies used for early gastric cancer with positive horizontal or indeterminable margins after ESD are presented in $>$ Table $\mathbf{S 1}$ and $>$ Fig. 3 . A total of 98 patients with early gastric cancer were treated within 30 days of ESD treatment initiation: repeat ESD (re-ESD), $n=14$ (14\%), 4 institutions; coagulation, $\mathrm{n}=55$ (56\%), 6 institutions; and surgical resection, $n=29$ (30\%), 7 institutions. Early re-ESD was completed safely in all 14 cases without any complications such as perforation or post-treatment bleeding. Residual cancer was demonstrated in the re-ESD specimens in 6 cases (43\%). Coagulati- on was performed safely in all 55 cases. Recurrence after coagulation was observed in 5 cases (9\%) in which coagulation was performed additionally. Local residual cancers were observed in 13 of 29 surgically resected specimens (45\%). Lymph node metastasis was not demonstrated in any surgically treated cases.

Pooled estimates of follow-up rate without early intervention in 14 institutions are demonstrated in $>$ Fig. 4. The proportion of patients who were followed up without early intervention in those with horizontal or indeterminable margins ranged from $30 \%$ to $100 \%$. The pooled estimate was $68 \%$ 


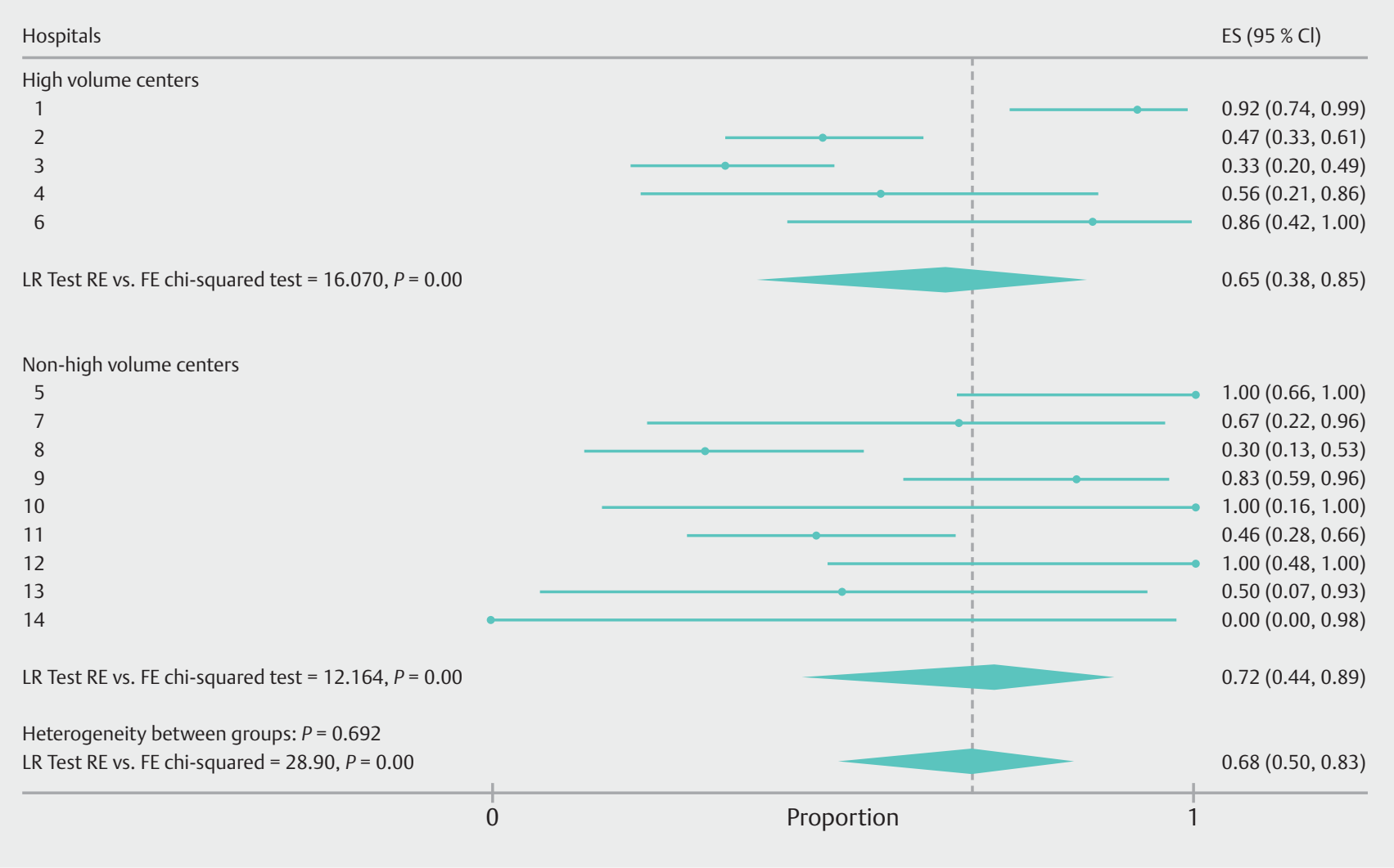

- Fig. 4 Pooled estimates of follow-up rate without early intervention in high and non-high volume centers.

(95\% Cl: $50 \%-83 \%$ ). The pooled estimates of high- and nonhigh-volume centers were $65 \%(95 \% \mathrm{Cl}: 38 \%-85 \%)$ and $72 \%$ ( $95 \% \mathrm{Cl}: 44 \%-89 \%$ ), respectively. Pooled estimates of these subgroups were not heterogeneous $(P=0.692)$.

Results of follow-up cases without early intervention are demonstrated in TableS2. In total, 131 cases were followed up without additional early treatments after initial ESD; 27 cases $(21 \%)$ recurred locally during the median follow-up period of 6 months (range, 1-74 months). The strategies used for the 27 recurrent cases more than 30 days after initial ESD were as follows ( $>$ Table S3): re-ESD, $n=13,6$ institutions; coagulation, $n=4,3$ institutions; surgical resection, $n=7,5$ institutions; and further observation or death due to other diseases, $n=3,2$ institutions. Late coagulation was performed safely in all 4 cases without any complications such as perforation or posttreatment bleeding. However, recurrence occurred in 3 coagulation cases $(75 \%)$, in which additional coagulation was performed. Lymph node or distant metastases were not found in the resected specimens from the seven surgically-treated patients. Additional treatments were not performed and observation was done in three locally recurrent cases due to the patient's decision and/or comorbid cardiopulmonary diseases.

Results of late re-ESD for recurrent cases are demonstrated in $>$ Table 1. The median size of the residual cancers and that of the resected specimens were $12 \mathrm{~mm}$ (range, 6-41 mm) and 40 $\mathrm{mm}$ (range, $20-59 \mathrm{~mm}$ ), respectively. The median procedural time was $133 \mathrm{~min}$ (range, $70-353 \mathrm{~min}$ ). The rate of en bloc re- section was $92 \%(12 / 13)$ in the late re-ESD group. Recurrence after late re-ESD occurred in the piecemeal resected case, in which a third ESD was performed and there was no recurrence during the follow-up period of 13 months after the third ESD. Needle-type knives (Dual knife/Flush knife/Flex knife), hook knives, and insulated tip (IT)-type knives (IT knife/IT knife 2) were preferred, and scissor-type grasping knives (SB knife/ Clutch cutter) were not selected during re-ESD procedure. Perforation and post-ESD bleeding did not occur in any case.

\section{Discussion}

This is the first report of a multicenter survey of treatment strategies for early gastric cancer with positive horizontal or indeterminable margins after ESD. The pooled estimates of positive margins in high-volume centers (1\%) were less than those in non-high-volume centers $(2 \%)$ in our study. Although the heterogeneous test between above 2 groups was not statistically significant $(P=0.191)$, this test lacks power. Kakushima et al reported that there were 3 types of lesions that resulted in positive margins after resection (lesions with a flat spreading area, lesions with an unexpected nearby lesion, and lesions with lateral extension beneath non-cancerous mucosa) and tumor diameter, recurrent-type cancer, submucosal cancer, and undifferentiated-type cancer were factors significantly related to margin-positive resection [3]. Therefore, early gastric can- 
- Table 1 Results of repeat ESD for locally recurrent lesions $(n=13)$.

\begin{tabular}{|l|c|}
\hline Median size of residual cancers (range) (mm) & $12(6-41)$ \\
\hline Median size of resected specimens (range) (mm) & $40(20-59)$ \\
\hline Median procedure time (range) (min) & $133(70-353)$ \\
\hline En bloc resection rate (\%) & $92 \%(12 / 13)$ \\
\hline Pathological tumor-free margin rate (\%) & $92 \%(12 / 13)$ \\
\hline Histopathologic depth (mucosa/submucosa) & $13 / 0$ \\
\hline Lymph vascular involvement (negative/positive) & $13 / 0$ \\
\hline Curative resection rate (\%) & $92 \%(12 / 13)$ \\
\hline Complication (bleeding/perforation) & $0 / 0$ \\
\hline Preferred knives (Needle type/Hook type/IT type) & $5 / 3 / 3$ \\
\hline ESD, endoscopic submucosal dissection; IT type, Insulated-tip type
\end{tabular}

cers with these factors may need to be treated in high-volume centers.

A first, and difficult, decision is whether the cases are treated promptly or followed up. In the current study, early treatment (early re-ESD, coagulation, or surgery) was performed in 98 cases (43\%), and 131 cases (57\%) were followed up without additional early treatments. In addition, pooled estimates of the follow-up rate without early intervention in high- and nonhigh-volume centers were not heterogeneous $(P=0.692)$. Recently, a cancer-positive lateral margin length $\geq 6 \mathrm{~mm}$ in the ESD specimens has been reported as an independent risk factor for local recurrence after ESD [5,6]. Before deciding whether the cases with positive horizontal or indeterminable margins are treated promptly or followed up, the length of cancer-positive lateral margins may need to be evaluated in the ESD specimens.

A second difficult decision is how to treat the cases with positive horizontal or indeterminable margins at an early date. ReESD, coagulation, or surgery were used in additional treatments within 30 days in the enrolled cases. With time, submucosal fibrosis becomes severe and it can be considered difficult to resect the residual cancers endoscopically. Coagulation was performed in 55 cases at 6 institutions (56\%). Admittedly, coagulation is easy and convenient. That may be the reason why coagulation was used to treat more than half of the enrolled cases. However, a specimen is not obtained and the state of residual cancers cannot be determined. Therefore, follow-up should be conducted more carefully. On the other hand, specimens can be obtained in re-ESD or surgery. In the early re-ESD group, ESD was completed safely in all cases and specimens were obtained. As a result, the re-ESD specimens could be evaluated pathologically and intramucosal residual cancer was demonstrated in 6 cases (43\%). Early gastrectomy was performed in 29 cases. However, local residual cancers were observed in 13 of 29 surgically resected specimens (45\%) and lymph node metastasis was not demonstrated in any cases. Early gastrectomy can be considered highly invasive.

The third choice is how to manage the later recurrent cases after follow-up. Application of coagulation to the later recur- rent lesions may be easy and convenient as in the cases treated at an early date. However, the recurrence rate was high in late coagulation cases (75\%) and coagulation may not be sufficient for the treatment of later recurrent lesions. As in the cases treated at an early date, lymph node or distant metastases were not found in the cases treated surgically at a later stage and local resection may be sufficient for the treatment of these lesions. En bloc resection rate was high (92\%) and the recurrent case after late ESD was treated using a third ESD. In addition, there were no complications in the late re-ESD group. Because locally recurrent cancers were within the mucosal layer and ESD is less invasive than gastrectomy, ESD may be considered a more suitable additional treatment for locally recurrent lesions, as suggested in previous reports [7-9].

There were several serious limitations in our study. First, the probability of positive horizontal or indeterminable margin should be collected not from the questionnaire, but from official reports such as published literatures. Therefore, information bias was inevitable. Second, the selection criteria were insufficient because institutions that responded to our questionnaire were not selected randomly and limited in Tokyo, Japan. This study was approved by the internal review boards only in these 14 institutions. Third, the detailed follow-up results after ESD and additional treatments were not asked in our questionnaire. Therefore, the effectiveness of each strategy for early gastric cancer with positive horizontal or indeterminable margins after ESD could not be evaluated.

\section{Conclusion}

In conclusion, the rate of positive margins after ESD tended to be lower in high volume centers. There was insufficient consensus regarding the treatment strategies used for early gastric cancer with positive horizontal or indeterminable margins after ESD. Therefore, further studies are required to establish a consensus.

\section{Acknowledgements}

The endoscopic gastric mucosal resection (EGMR) conference was supported by Eisai Co., Ltd.

\section{Competing interests}

None

References

[1] Ono H, Kondo H, Gotoda T et al. Endoscopic mucosal resection for treatment of early gastric cancer. Gut 2001; 48: 225-229

[2] Neuhaus H, Costamagna G, Deviere J et al. Endoscopic submucosal dissection (ESD) of early neoplastic gastric lesions using a new double-channel endoscope (the "R-scope"). Endoscopy 2006; 38: 1016 1102 
[3] Kakushima N, Ono H, Tanaka M et al. Factors related to lateral margin positivity for cancer in gastric specimens of endoscopic submucosal dissection. Dig Endosc 2011; 23: 227 - 232

[4] Sekiguchi M, Suzuki H, Oda I et al. Favorable long-term outcomes of endoscopic submucosal dissection for locally recurrent early gastric cancer after endoscopic resection. Endoscopy 2013; 45: 708 - 713

[5] Sekiguchi M, Suzuki H, Oda I et al. Risk of recurrent gastric cancer after endoscopic resection with a positive lateral margin. Endoscopy 2014; 46: 273-278

[6] Kim TK, Kim GH, Park do Y et al. Risk factors for local recurrence in patients with positive lateral resection margins after endoscopic submucosal dissection for early gastric cancer. Surg Endosc 2015; 29: $2891-2898$
[7] Higashimaya M, Oka S, Tanaka S et al. Endoscopic submucosal dissection for residual early gastric cancer after endoscopic submucosal dissection. Gastrointest Endosc 2013; 77: 298-302

[8] Hoteya S, lizuka T, Kikuchi D et al. Secondary endoscopic submucosal dissection for residual or recurrent tumors after gastric endoscopic submucosal dissection. Gastric Cancer 2014; 17: 697 - 702

[9] Shimamura Y, Ishii N, Nakano K et al. Repeat endoscopic submucosal dissection for recurrent gastric cancers after endoscopic submucosal dissection. World J Gastrointest Endosc 2013; 5: 600-604

[10] The Japanese Gastric Cancer Association. Japanese gastric cancer treatment guidelines 2010. (ver. 3). Gastric Cancer 2011; 14: 113 123

[11] Nyaga VN, Arbyn M, Aerts M. Metaprop: a Stata command to perform meta-analysis of binomial data. Arch Public Health 2014; 72: 39 


\section{Questionnaires of the strategies used for early gastric cancer with positive horizontal or indeterminable margins after endoscopic submucosal} dissection (ESD).

Hospital

Delegate

Q1. The number of gastric cancers treated with ESD so far? cases from month/year (____ _ $)$ to month/year (__ _ _ $)$

Q2. The number of the cases in which the tumors were diagnosed as T1a and either no ulcer findings regardless of size or positive ulcer findings in tumors sized $\leq 3 \mathrm{~cm}$ in diameter, and positive horizontal or indeterminable margins were demonstrated in the ESD-specimens. cases

Q3. Strategies for Q2 cases

(1) Early repeat ESD (re-ESD) (ESD within 30 days after initial ESD)

(2) Early coagulation (coagulation within 30 days after initial ESD) cases

(3) Early gastrectomy (additional gastrectomy without follow-up) cases

(4) Follow-up without early treatments cases

Q4. Results of early re-ESD (Q3 (1))
A. Perforation cases
B. Uncontrollable bleeding cases
C. The number of the cases in which residual cancer was demonstrated in the re-ESD specimens cases

Q5. Results of early coagulation (Q3 (2))
A. Perforation
cases
B. Uncontrollable bleeding cases
C. Recurrence after early coagulation Additional treatments for recurrent cases (_

Q6. Results of early gastrectomy (Q3 (3))

A. The number of the cases in which residual cancer was demonstrated in the surgically resected stomach.

B. The number of the cases in which lymph node metastasis was observed in the resected specimens. cases

Q7. Results of follow-up cases (Q3 (4))
A. No recurrence cases
B. Local recurrence cases
C. Lymph node metastasis or distant metastasis cases

Q8. Duration from initial ESD to recurrence in the follow-up cases (Q3 (4)) a. Local recurrence $(\mathrm{Q} 7 \mathrm{~B})$

Case 1 months
Case 2—months
Case 3ـmonths

b. Lymph node metastasis or distant metastasis(Q7 C)

$\begin{array}{ll}\text { Case } 1 & \text { months } \\ \text { Case 2 months } & \\ \text { Case 3 months }\end{array}$

29. Additional treatments for local recurrent cases (Q7 B)

I. Re-ESD cases

II. Coagulation ___ cases

III. Gastrectomy ___ cases

IV. No treatment ___ cases

Q10. Results of re-ESD in local recurrent cases after follow-up (Q9 I)

I. En bloc resection __ cases

II. Piecemeal resection ___ cases

III. Diameter of recurrent tumors

Case $1 \longrightarrow \mathrm{mm}$
Case $2 \longrightarrow \mathrm{mm}$
Case $3 \longrightarrow \mathrm{mm}$

Case $3 \quad \mathrm{~mm}$

IV. Diameter of the resected specimens

Case 1 mm

Case $2 \longrightarrow \mathrm{mm}$

Case $3 \longrightarrow \mathrm{mm}$

V. Procedural time

Case 1 min

Case $2 \ldots$ min

Case 3 min

VI. Perforation __ cases

VII. Uncontrollable bleeding ___ cases

VIII. R0 cases R1_cases

IX. Recurrence after re-ESD ___ cases Clinical course in recurrent cases after re-ESD

$X$. Follow-up periods after re-ESD

Case $1 \longrightarrow \mathrm{mm}$

Case $3 \longrightarrow \mathrm{mm}$

Q11. What devices do you prefer during re-ESD procedure? Check up to 2 knives.

$\square$ Dual knife/Flush knife/Flex knife $\square$ Hook knife

$\square$ SB knife/Clutch cutter $\square$ IT knife/IT knife 2

$\square$ Others

Q12. Results of coagulation (Q9 II)

I. Perforation cases

II. Uncontrollable bleeding

III. Recurrence after coagulation ___ cases Additional treatments for recurrent cases

Q13. Results of gastrectomy (Q9 III)

I. The number of the cases in which residual cancer was demonstrated in the surgically resected stomach. cases

II. The number of the cases in which lymph node metastasis was observed in the resected specimens. Detailed clinical course of recurrent cases cases

Q14. Reasons of follow-up without intervention (Q9 IV)

Case 1

Case 2

Fig. S1 Questionnaires of the strategies used for early gastric cancer with positive horizontal or indeterminable margins after endoscopic submucosal dissection (ESD). 
- TableS1 Management of early gastric cancers with positive horizontal or indeterminable margins after initial ESD.

\begin{tabular}{|c|c|c|c|c|c|c|c|c|}
\hline Institutions & $\begin{array}{l}\text { Total } \\
\text { ESD } \\
\text { (Q1) }\end{array}$ & $\begin{array}{l}\text { Data collection period } \\
\text { (From month/year to } \\
\text { month/year) }\end{array}$ & $\begin{array}{l}\text { ESD } \\
\text { cases/ } \\
\text { year }\end{array}$ & $\begin{array}{l}\text { HM1 } \\
\text { cases } \\
\text { (Q2) }\end{array}$ & $\begin{array}{l}\text { Early } \\
\text { ESD } \\
\text { (Q3 (1) }\end{array}$ & $\begin{array}{l}\text { Early } \\
\text { coagulation } \\
\text { (Q32) }\end{array}$ & $\begin{array}{l}\text { Early } \\
\text { surgery } \\
\text { (Q33) }\end{array}$ & $\begin{array}{l}\text { Follow- } \\
\text { up } \\
\text { (Q3 (4) }\end{array}$ \\
\hline 1 & 2686 & Jan/2003-Mar/2014 & 241 & 25 & 0 & 0 & 2 & 23 \\
\hline 2 & 2042 & $\mathrm{Apr} / 2005-\mathrm{Mar} / 2013$ & 255 & 53 & 11 & 2 & 15 & 25 \\
\hline 3 & 1819 & Sep/2002 - Apr/2014 & 157 & 40 & 0 & 21 & 4 & 15 \\
\hline 4 & 1274 & May/2007-Mar/2014 & 186 & 8 & 1 & 0 & 2 & 5 \\
\hline 5 & 762 & Apr/2004-May/2014 & 75 & 9 & 0 & 0 & 0 & 9 \\
\hline 6 & 690 & Aug/2008 - May/2014 & 118 & 7 & 1 & 0 & 0 & 6 \\
\hline 7 & 627 & Oct/2003 - May/2014 & 59 & 6 & 0 & 0 & 2 & 4 \\
\hline 8 & 500 & Jan/2004- Oct/2013 & 51 & 23 & 0 & 14 & 2 & 7 \\
\hline 9 & 500 & Jan/2006 - May/2014 & 60 & 18 & 1 & 2 & 0 & 15 \\
\hline 10 & 270 & Jan/2010-Mar/2014 & 65 & 2 & 0 & 0 & 0 & 2 \\
\hline 11 & 252 & Dec/2006 - May/2014 & 34 & 28 & 0 & 15 & 0 & 13 \\
\hline 12 & 209 & Jun/2010-Dec/2013 & 60 & 5 & 0 & 0 & 0 & 5 \\
\hline 13 & 100 & Jan/2003-Apr/2014 & 9 & 4 & 0 & 0 & 2 & 2 \\
\hline 14 & 65 & $\mathrm{Apr} / 2013-\mathrm{Mar} / 2014$ & 65 & 1 & 0 & 1 & 0 & 0 \\
\hline Total & 11796 & & & 229 & 14 & 55 & 29 & 131 \\
\hline $\begin{array}{l}\text { ESD, endoscop } \\
\text { Q2. The numbe } \\
\leq 3 \mathrm{~cm} \text { in diam } \\
\text { Q3. Strategies } \\
\text { Early repeat ES } \\
\text { Early coagulati } \\
\text { Early gastrecto } \\
\text { Follow-up with }\end{array}$ & $\begin{array}{l}\text { the cases } \\
\text { the and posi } \\
\text { e-ESD) (ES } \\
\text { coagulati } \\
\text { (addition } \\
\text { early trea }\end{array}$ & $\begin{array}{l}\text { ection; HM1, positive horizor } \\
\text { hich the tumors were diagno } \\
\text { orizontal or indeterminable } \\
\text { thin } 30 \text { days after initial ESD) } \\
\text { thin } 30 \text { days after initial ESD) } \\
\text { trectomy without follow-up) }\end{array}$ & $\begin{array}{l}\text { or indete } \\
\text { as T1a an } \\
\text { jins were }\end{array}$ & $\begin{array}{l}\text { able mar } \\
\text { cher no ul } \\
\text { honstrate }\end{array}$ & $\begin{array}{l}\text { findings re } \\
\text { the ESD-s }\end{array}$ & $\begin{array}{l}\text { ss of size or posit } \\
\text { ens. }\end{array}$ & findings in & rs sized \\
\hline
\end{tabular}


- Table S2 Results of follow-up cases without early interventions.

\begin{tabular}{|c|c|c|c|c|}
\hline Institutions & $\begin{array}{l}\text { Follow-up cases } \\
\text { without early treatments (Q3 (4)) }\end{array}$ & $\begin{array}{l}\text { No recurrence } \\
\text { (Q7A) }\end{array}$ & $\begin{array}{l}\text { Local recurrence } \\
\text { (Q7B) }\end{array}$ & $\begin{array}{l}\text { Lymph node or distant metastasis } \\
\text { (Q7C) }\end{array}$ \\
\hline 1 & 23 & 17 & 6 & 0 \\
\hline 2 & 25 & 17 & 8 & 0 \\
\hline 3 & 15 & 12 & 3 & 0 \\
\hline 4 & 5 & 4 & 1 & 0 \\
\hline 5 & 9 & 6 & 3 & 0 \\
\hline 6 & 6 & 6 & 0 & 0 \\
\hline 7 & 4 & 3 & 1 & 0 \\
\hline 8 & 7 & 6 & 1 & 0 \\
\hline 9 & 15 & 14 & 1 & 0 \\
\hline 10 & 2 & 0 & 2 & 0 \\
\hline 11 & 13 & 13 & 0 & 0 \\
\hline 12 & 5 & 4 & 1 & 0 \\
\hline 13 & 2 & 2 & 0 & 0 \\
\hline 14 & 0 & 0 & 0 & 0 \\
\hline Total & 131 & 104 & 27 & 0 \\
\hline
\end{tabular}

- Table S3 Additional treatments for local recurrent cases after initial ESD.

\begin{tabular}{|c|c|c|c|c|c|}
\hline Institutions & $\begin{array}{l}\text { Local Recurrence } \\
\text { after follow-up (Q7B) }\end{array}$ & $\begin{array}{l}\text { Re-ESD } \\
\text { (Q9I) }\end{array}$ & $\begin{array}{l}\text { Coagulation } \\
\text { (Q9PII) }\end{array}$ & $\begin{array}{l}\text { Surgery } \\
\text { (Q9III) }\end{array}$ & $\begin{array}{l}\text { No treatment } \\
\text { (Q9IV) }\end{array}$ \\
\hline 1 & 6 & 4 & 0 & 2 & 0 \\
\hline 2 & 8 & 5 & 1 & 2 & 0 \\
\hline 3 & 3 & 1 & 2 & 0 & 0 \\
\hline 4 & 1 & 0 & 0 & 0 & 1 \\
\hline 5 & 3 & 1 & 0 & 0 & 2 \\
\hline 6 & 0 & 0 & 0 & 0 & 0 \\
\hline 7 & 1 & 0 & 0 & 1 & 0 \\
\hline 8 & 1 & 0 & 0 & 1 & 0 \\
\hline 9 & 1 & 1 & 0 & 0 & 0 \\
\hline 10 & 2 & 1 & 1 & 0 & 0 \\
\hline 11 & 0 & 0 & 0 & 0 & 0 \\
\hline 12 & 1 & 0 & 0 & 1 & 0 \\
\hline 13 & 0 & 0 & 0 & 0 & 0 \\
\hline 14 & 0 & 0 & 0 & 0 & 0 \\
\hline Total & 27 & 13 & 4 & 7 & 3 \\
\hline
\end{tabular}

